\title{
Improvement of dynamic characteristics of manipulator driven by a gas-liquid phase-change actuator using an antagonistic drive
}

\author{
Tomonori Kato ${ }^{1,}$, Kenya Higashijima ${ }^{1}$, Yusuke Kuradome ${ }^{1}$, Kohei Noguchi $^{1}$, and Manabu Ono ${ }^{2}$ \\ ${ }^{1}$ Department of Intelligent Mechanical Engineering, Faculty of Engineering, Fukuoka Institute of Technology, Fukuoka, Japan \\ ${ }^{2}$ Monozukuri Department, Tokyo Metropolitan College of Industrial Technology, Tokyo, Japan
}

\begin{abstract}
The goal of this research is to improve the dynamic characteristics of a manipulator composed of pneumatic artificial rubber muscles driven by gas-liquid phase change. Pneumatic actuators, such as pneumatic artificial rubber muscle (PARM) or rubber bellows, have been widely used in many industrial and research fields. They have merits of being compact and lightweight. However, the large size of the compressor driving the actuator is a problem. To overcome this, the authors researched soft actuators driven by the gas-liquid phase change (GLPC) of fluorocarbon. Fluorocarbon $\left(\mathrm{C}_{5} \mathrm{~F}_{11} \mathrm{NO}\right)$ is a substance with a relatively low boiling point $\left(50^{\circ} \mathrm{C}\right)$ and a low heat of evaporation $(104.65 \mathrm{~kJ} / \mathrm{kg})$. The heat of evaporation of water is $2260 \mathrm{~kJ} / \mathrm{kg}$. This paper presents the overview of an actuator driven by GLPC. Then, fabrication of a manipulator using the GLPC driven PARM, and details of experiments conducted to determine manipulator characteristics are given. To improve the dynamic characteristics of the manipulator, a force control method using the antagonistic drive of two PARMs is proposed, and experiments are conducted to validate the effectiveness of the proposed method.
\end{abstract}

\section{Introduction}

A pneumatic artificial rubber muscle (PARM) is a pneumatically driven actuator that imitates muscle contraction. As shown in Fig. 1, when the inside is pressurized, PARM expands in a radial direction, shrinking and generating a pulling force in the axial direction. Several studies have applied PARMs to robots that contact humans, because PARMs have beneficial properties, such as light weight and flexibility [1] [2]. However, a PARM requires many cumbersome peripheral devices, such as a compressor, pressure regulators, servo valves, and piping to drive it. (Fig.2).

To solve this problem and to realize a compact PARM driving system, the authors researched PARM drives using gas-liquid phase-change of fluorocarbon (GLPC) instead of a compressor and other peripheral devices. At the initial stage of our research (2000-2010), it took more than $200 \mathrm{~s}$ to generate the adequate pressure to drive an actuator with GLPC [3].

Therefore, in recent years, we studied the dynamic response of GLPC-driven PARM by modifying the structure of the actuator and applying a feedback control scheme. Thus, the pressure response was improved [4]. Particularly, when the inside pressure was raised, the time constant of the pressure of less than $1 \mathrm{~s}$ was realized [5]. Thus, PARMs, driven by GLPCs, can apply to many practical problems. However, when the inside pressure is reduced, the time constant tends to be larger, because cooling the fluorocarbon takes longer than heating it.
In this paper, the overview of the GLPC-driven actuator is first explained. Second, design and fabrication of the manipulator is explained, and the result of the gripping experiment is shown. Third, to compensate the dynamic characteristics of the manipulator, the force control method using antagonistic drive of two PARMs is proposed and experiments are conducted to validate the effectiveness of the proposed method.

\section{Manipulator driven by GLPC}

\subsection{Concept of a GLPC-driven actuator}

GLPC is a phenomenon in which a substance transitions from liquid to gas or from gas to liquid. When a liquid is heated, it begins to boil and transitions to a gas. This transition causes its volume to expand and the pressure in the container to increase. When the substance is removed from the heat source, it loses its energy and returns to the liquid phase because of the heat transfer from inside the container to the ambient environment. Consequently, the substance volume contracts and the pressure decreases. Fig. 3 illustrates the concept of an actuator driven by GLPCs.

The actuator takes advantage of volume expansion during the liquid-to-gas phase change. A working fluid is added to an actuator, such as a PARM, and an electric heater (e.g., constantan heater) is installed. When the

\footnotetext{
Corresponding author: t-kato@fit.ac.jp
} 


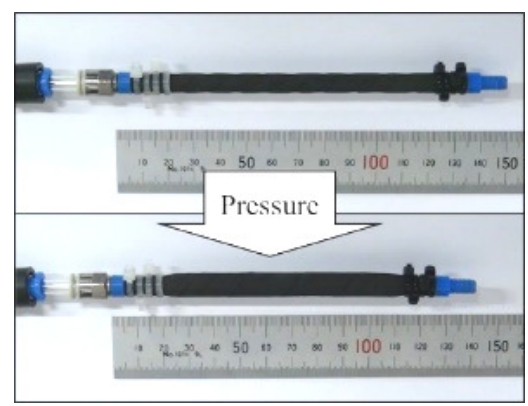

Fig. 1 Pneumatic artificial rubber muscle.

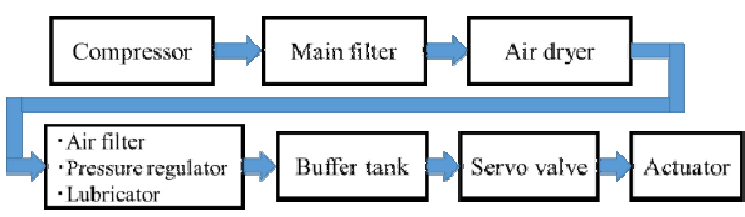

Fig. 2 Pneumatic components driving PARM.

heater in the actuator is powered on, the heated liquid expands and boils into gas. The actuator is driven by the pressure generated by the volume expansion because of the thermal expansion of the liquid and the following GLPC. When the heat source is removed, the generated gas returns to liquid and the volume contracts. Because the GLPC actuator does not require a compressor or other peripheral pneumatic components, it is possible to miniaturize the entire apparatus for driving the actuator.

In this study, fluorocarbon $\left(\mathrm{C}_{5} \mathrm{~F}_{11} \mathrm{NO}\right)$ is used as the working fluid. Its characteristics are compared to those of water, and presented in Table 1. Because this fluorocarbon has a low boiling point of $50{ }^{\circ} \mathrm{C}$ at atmospheric pressure, and a vaporization heat of 104.65 $\mathrm{kJ} / \mathrm{kg}$, which is $1 / 22$ that of water $(2260 \mathrm{~kJ} / \mathrm{kg})$, a small thermal energy supply can induce the liquid-to-gas phase change. The coefficient of thermal expansion of the fluorocarbon at $20{ }^{\circ} \mathrm{C}$ is $0.00154{ }^{\circ} \mathrm{C}^{-1}$, which is approximately seven times that of water. Moreover, it is non-poisonous and incombustible, and its properties are not changed by heating, according to its product manual issued by $3 \mathrm{M}$. Thus, this working fluid is suitable for use in the GLPC actuator.

\subsection{Robotic manipulator driven by PARM using GLPC}

A manipulator whose driving force is generated by a PARM using GLPCs is designed and fabricated. The image and that of the controlling devices of the fabricated manipulator are shown in Figs. 4 and 5. The PARM used in this research is FESTO MXAM-5-AA. Beneath the PARM, a fixed container with a volume of $3.93 \mathrm{~cm}^{3}$ is installed. The PARM and the container are filled with the fluorocarbon working fluid, which is heated and boiled by powering the constantan heater (Tokyo Wire Works, Ltd., diameter: $0.231 \mathrm{~mm}$, resistance per length: $16.02 \Omega / \mathrm{m}$, total resistance: 20.6 $\Omega$ ) at the bottom of the container. Additionally, a pressure sensor (SMC PSE510-R06) is installed between the PARM and the container. The control signal (voltage: $0-10 \mathrm{~V}$ ) is generated by the digital signal processor (DSP) (i.e., MTT s-BOX). By inputting the control signal into the power source, a voltage of $0-35 \mathrm{~V}$ is applied to the heater. The working fluid in the container is heated by the heater to induce the GLPC. According to the kinematic calculation, when the pulling force generated by the PARM is $20 \mathrm{~N}$, the hand can generate a gripping force of about $2.57 \mathrm{~N}$.

A PI feedback control was utilized to control the temperature as shown in Fig. 6. The PI control gains were set as follows. Proportional gain was set to 1000 $\mathrm{V} / \mathrm{Pa}$, and integral gain was set to $3 \mathrm{~V} /(\mathrm{Pa} \cdot \mathrm{s})$. The

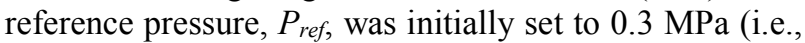
gauge). At $40 \mathrm{~s}, P_{\text {ref }}$ was increased to $0.35 \mathrm{MPa}$. Then, at $80 \mathrm{~s}$, it was decreased back to $0.3 \mathrm{MPa}$. The gripping force was measured by a load cell (Tokyo Sokki, TCLZ20NA, Dynamic Strain Meter DA-18A). The generated pressure $P$, gripping force $F$, and voltage to the heater $E$, were measured by the data logger.

The experimental results are shown in Fig. 7. The time constants were $0.18 \mathrm{~s}$ when the pressure was increased from 0.3 to $0.35 \mathrm{MPa}$ and $1.35 \mathrm{~s}$ when the pressure was decreased from 0.35 to $0.3 \mathrm{MPa}$. During $40-80 \mathrm{~s}$, the pressure $P$ was kept nearly steady at 0.35 $\mathrm{MPa}$. Therefore, the gripping force was kept at $2.57 \mathrm{~N}$.

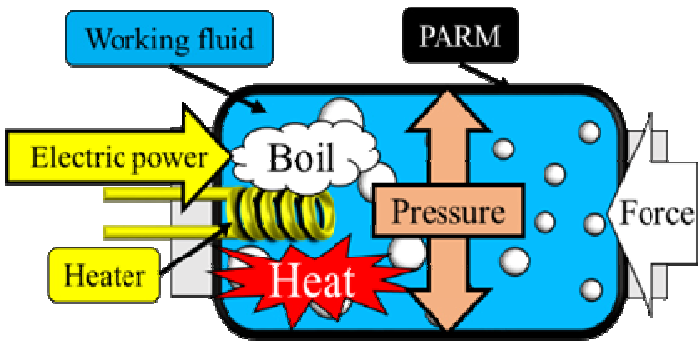

Fig. 3 Concept of the GLPC-driven actuator

Table 1. Characteristics of working fluid compared to water.

\begin{tabular}{|c|c|c|c|}
\hline $\begin{array}{c}\text { Working fluid } \\
\text { (Chemical } \\
\text { formula) }\end{array}$ & $\begin{array}{c}\text { Boiling } \\
\text { point } \\
(1 \mathrm{~atm})\left[{ }^{\circ} \mathrm{C}\right]\end{array}$ & $\begin{array}{c}\text { Heat of } \\
\text { vaporization } \\
{[\mathrm{kJ} / \mathrm{kg}]}\end{array}$ & $\begin{array}{c}\text { Coefficient of } \\
\text { thermal } \\
\text { expansion }\left[{ }^{\circ} \mathrm{C}^{-1}\right]\end{array}$ \\
\hline $\begin{array}{c}\text { Fluorocarbon } \\
\left(\mathrm{C}_{5} \mathrm{~F}_{11} \mathrm{NO}\right)\end{array}$ & 50 & 104.65 & 0.00154 \\
\hline $\begin{array}{c}\text { Water } \\
\left(\mathrm{H}_{2} \mathrm{O}\right)\end{array}$ & 100 & 2257 & 0.00021 \\
\hline
\end{tabular}

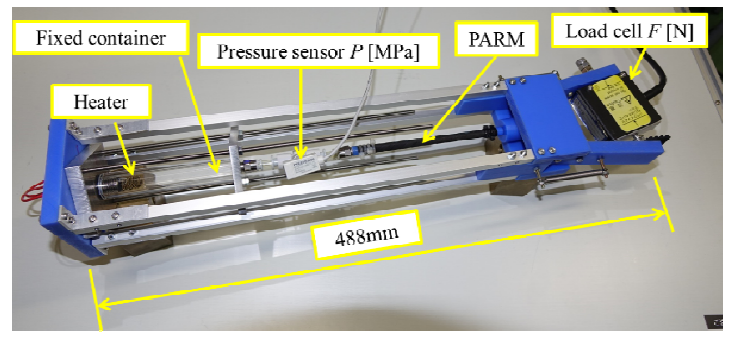

Fig. 4 Fabricated manipulator. 


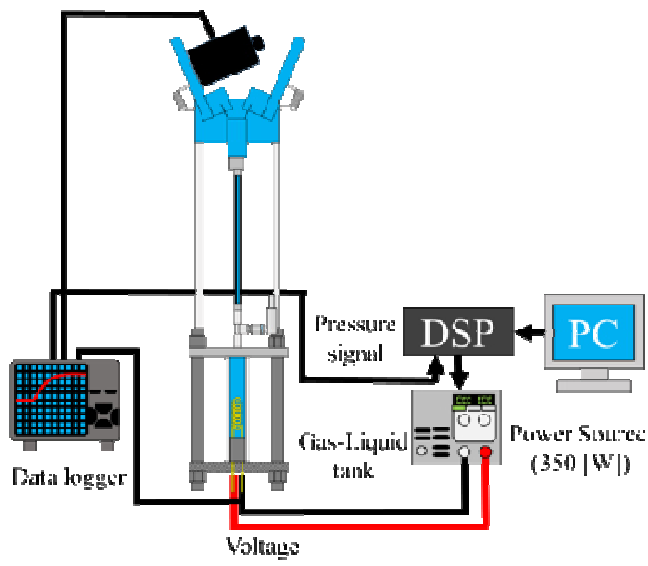

Fig. 5 Controlling devices of the manipulator.

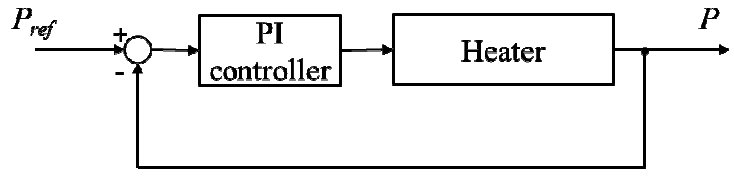

Fig. 6 Block diagram of PI feedback control.

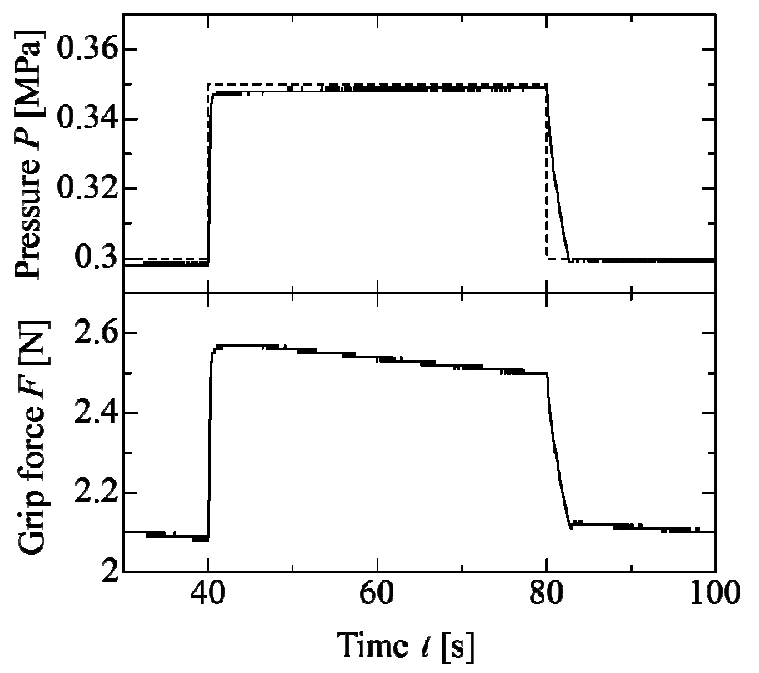

Fig. 7 Results of the manipulator gripping experiment.

\section{Compensation of dynamic characteristics}

\subsection{Force control of antagonistic drive of 2 PARMs}

Response of the PARM driven by GLPC is slow, particularly when the inside is depressurized. To solve this problem, an antagonistic drive system shown in Fig. 8 is designed and fabricated. The device is composed of two PARMs, a gear-wheel, a chain, and a rod. At the tip of the rod, a load cell is set. Because the two PARMs are antagonistically driven, when PARM A is contracted (i.e., pressurized), PARM B is not contracted, and torque $\tau[\mathrm{N} \mathrm{m}]$ is generated. Therefore, pushing force $F^{\prime}[\mathrm{N}]$ is generated at the tip of the rod. The antagonistic drive system is especially beneficial when repeating force change is required, because PARM A and PARM B can alternately generate pulling force.

The fabricated device is shown in Fig. 9. The length of the rod and the diameter of the pully are indicated in the figure. With both PARM A and PARM B, PI pressure feedback control is conducted as in the previous section.

\subsection{Experimental procedures and results}

By using the experimental device shown in Fig. 9, repeating force control was performed to validate the effectiveness of the proposed antagonistic drive. The timing chart of the pressure reference values of both PARMs is shown in Fig. 10. In the experiment, both reference values were set at $0.3 \mathrm{MPa}$ (i.e., gauge). Then, at $40 \mathrm{~s}$, the reference value with PARM A was raised to $0.35 \mathrm{MPa}$. By geometric calculation, this should generate a pushing force of $F^{\prime}=0.65 \mathrm{~N}$. Third, at $80 \mathrm{~s}$, the reference value of PARM $B$ was raised to $0.36 \mathrm{MPa}$, whereas the value for PARM A was kept at $0.35 \mathrm{MPa}$. In the experiment, the pressure values in both PARM A and $\mathrm{B}$, and the pushing force $F^{\prime}[\mathrm{N}]$ were measured.

The experimental results are shown in Fig. 11, where the dark black line indicates the pushing force, $F^{\prime}[\mathrm{N}]$, measured at the tip of the rod. Between 40-80 s, the $F^{\prime}$ was kept at around $0.63-0.65 \mathrm{~N}$. Before $40 \mathrm{~s}$ and after $80 \mathrm{~s}$, the value was almost $0 \mathrm{~N}$. The time constants for the force $F^{\prime}[\mathrm{N}]$ were $0.78 \mathrm{~s}$ when increasing the force (soon after $40 \mathrm{~s}$ ) and $0.31 \mathrm{~s}$ when decreasing the force (soon after $80 \mathrm{~s}$ ).

A comparative experiment was conducted using the pressure reference values shown in Fig. 12. Because the value for PARM $B$ is unchanged throughout the experiment, this condition is close to a manipulator driving experiment using a single PARM, as explained in the last chapter. With the reference values shown in Fig. 13, the time constant when decreasing the force was $1.08 \mathrm{~s}$. The comparison of the experimental results with the proposed driving method and that of the comparative experiment are shown in Fig.13.

Therefore, the proposed antagonistic driving method can compensate the weak point in the dynamic characteristics of GLPC-driven PARM.

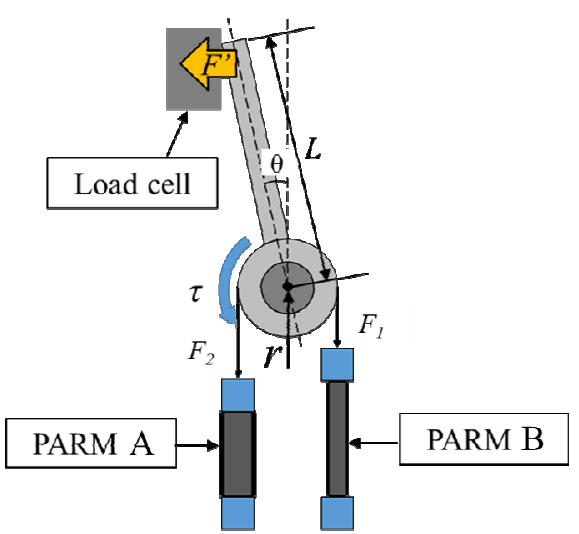

Fig. 8 Antagonistic drive system. 


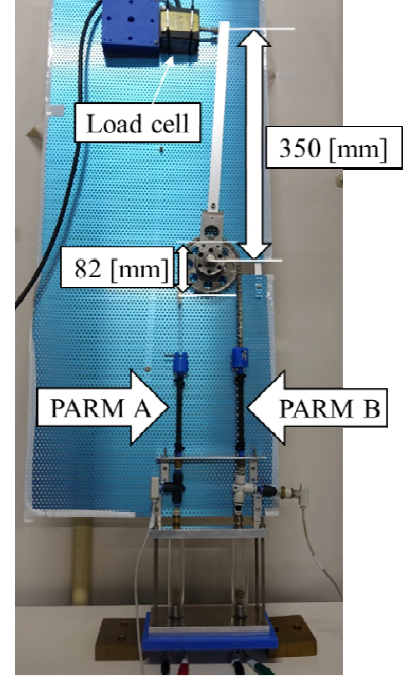

Fig. 9 Experimental device of the antagonistic drive.

\begin{tabular}{|c|c|c|c|c|}
\hline & & $0-40[s]$ & $40-80[s]$ & $80-120[s]$ \\
\hline \multirow{3}{*}{ PARM A } & $0.35[\mathrm{MPa}]$ & & & \\
\hline & & & & \\
\hline & 0.30 [MPa] & & & \\
\hline \multirow{3}{*}{ PARM B } & $0.36[\mathrm{MPa}]$ & & & \\
\hline & & & & \\
\hline & 0.30 [MPa] & & & \\
\hline
\end{tabular}

Fig. 10 Timing chart of the antagonistic drive system.

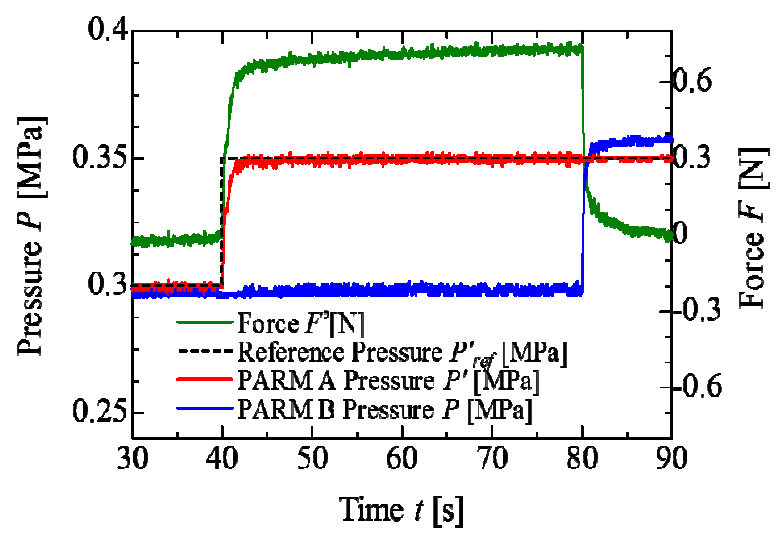

Fig.11 Experimental results of antagonistic driving device.

\begin{tabular}{|c|c|c|c|c|}
\hline & & $0-40[s]$ & $40-80[s]$ & $80-120[s]$ \\
\hline \multirow{2}{*}{ PARM A } & 0.35 [MPa] & & & \\
\hline & 0.30 [MPa] & & & \\
\hline \multirow{3}{*}{ PARM B } & 0.35 [MPa] & & & \\
\hline & $0.30[\mathrm{MPa}]$ & & & \\
\hline & & & & \\
\hline
\end{tabular}

Fig. 12 Timing chart of antagonistic drive system for the comparative experiment.

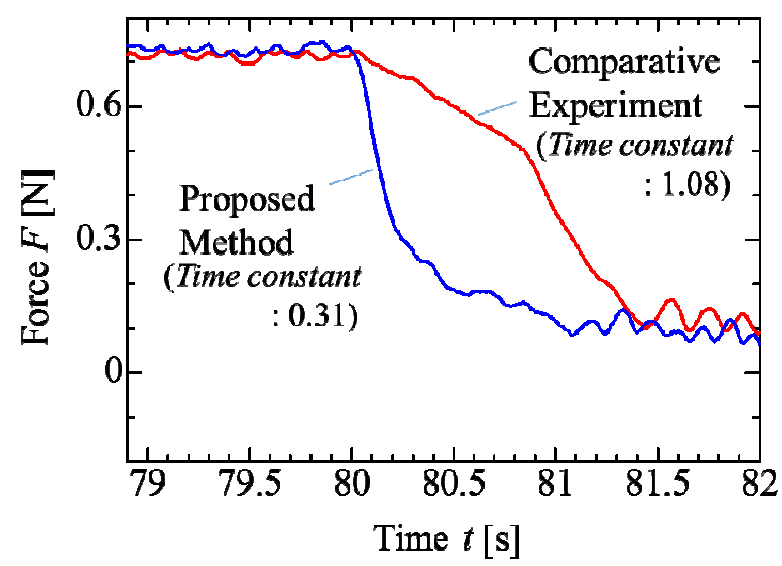

Fig. 13 Comparison of experimental results.

\section{Conclusions}

In this paper, first, we presented an overview of the actuator driven by GLPC.

Second, design and fabrication of a manipulator was explained, and the result of gripping experiment was presented.

Third, to compensate the dynamic characteristics of the manipulator, force control method using antagonistic drive of two PARMs was proposed, and experiments were conducted using a fabricated device. Experimental results show that the proposed control method can make the dynamic characteristics of GLPC-driven actuator faster, reducing the time constant value of force from $1.08 \mathrm{~s}$ to $0.31 \mathrm{~s}$.

\section{References}

1. T. Noritsugu. 1997. Pneumatic Actuators, $J$. Robotics Soc., Japan, 15(3), pp. 355-359.

2. K. Kawashima, T. Sasaki, T. Miyata, N. Nakamura, M. Sekiguchi, T. Kagawa. 2004. Development of Robot Using Pneumatic Artificial Rubber Muscles to Operate Construction Machinery, J. Robotics, Mechatronics, 16(1), pp. 8-15.

3. S. Matsuda, M. Ono, T. Izumi, S. Kato. 2005. Metal Bellows Type Gas-liquid Phase-change Actuator: Applications for Endoscopic Surgery Forceps, J. Japan Soc. for Precis. Engin., 71(6), pp. 723-728.

4. T. Kato, S. Honda, M. Cheng, K. Sakuragi, M. Ono. 2016. Fabrication of a Miniature Rubber Muscle Actuator Driven by Gas-Liquid Phase Change, $J$. Fluid Power Sys., 9(1), pp. 11-17.

5. K. Higashijima, T. Kato, K. Sakuragi, T. Sato, M. Ono. 2017. Development of Manipulator using a Gas-Liquid Phase-Change Actuator. 10th JFPS Intl. Symp. Fluid Power 2017, 2B04. 